\title{
APROPIACIÓN DIFERENCIAL Y PUESTA EN \\ PRODUCCIÓN DEL ESPACIO MISIONERO \\ EL CASO DEL ALTO URUGUAY: AVANCE DE LA FRONTERA \\ AGRARIA, HIPÓTESIS DE CONFLICTO Y CONSOLIDACIÓN \\ DEL TABACO
}

\section{Sergio BRATICEVIC ${ }^{2}$}

\section{Resumen}

En este breve artículo, el autor realiza un repaso sobre el proceso de puesta en producción del espacio misionero, comenzando desde el avance del frente extractivo de colonización, para llegar a la consolidación de la frontera agraria a mediados del siglo XX. Finalmente, complejiza el análisis sobre el Nordeste Provincial, mostrando las hipótesis de conflicto sobre la frontera con el Brasil - propias del discurso autoritario de época- antes de analizar la implantación definitiva del tabaco en la zona, a través del fenómeno de subsunción al trabajo.

Palabras Clave: Frontera Agraria, Proceso de Colonización, Hipótesis de Conflicto, Tabaco, Subsunción.

\begin{abstract}
In this brief article, the author presents a revision on the beginning of production in Misiones Province space, from the advance of the extractive colonization front, to reach the consolidation of the agrarian frontier in the middle of the twentieth century. Later, he analyzes this process in the Northeast Province area, showing the conflict hypothesis in the borderland with Brazil -as the synonymous of the authoritarian epoch discourse- before illustrating the definitive implantation of the tobacco in the zone, across the subsumption of labour process.
\end{abstract}

\footnotetext{
${ }^{1}$ Trabajo realizado en el marco del Proyecto de Investigación CONICET PIP 3051 "Transformaciones territoriales recientes en formaciones sociales de frontera. Programas de desarrollo y procesos de lucha en comunidades indígenas y campesinas en el Chaco Central y en la Cuenca Alta del Río Uruguay" asentado en el Instituto de Ciencias Antropológicas de la Facultad de Filosofía y Letras-UBA. La elaboración final del presente escrito es producto de la realización de diversos trabajos en campo entre Julio de 2009 y Agosto de 2011 en la localidad misionera de El Soberbio y las colonias aledañas. Con respecto a la recolección de información primaria, se realizaron entrevistas semiestructuradas. En relación a las fuentes secundarias se utilizaron estadísticas oficiales del Ministerio de Agricultura de Nación y del Instituto Provincial de Estadísticas y Censos de Misiones.

${ }^{2}$ Licenciado en Geografía y Doctor en Antropología Sergio Braticevic. Instituto de Ciencias Antropológicas, Facultad de Filosofía y Letras, Universidad de Buenos Aires-CONICET sergiobraticevic@gmail.com
}

Fecha de recepción del artículo: Octubre 2012

Fecha de evaluación: Noviembre 2012 


\section{Papeles de Trabajo $N^{\circ} 26$ - Diciembre 2013 - ISSN 1852-4508 \\ Centro de Estudios Interdisciplinarios en Etnolingüística y Antropología Socio-Cultural}

Key Words: Agrarian Frontier, Colonization Process, Conflict Hypothesis, Tobacco, Subsumption.

\section{Résumé}

Dans ce bref article, l'auteur réalise une révision sur le processus de origine dans production de l'espace dans la province de Misiones, en commençant depuis l'avance du front extractif de colonisation, pour arriver à la consolidation du front pionnier vers le milieu du XXe siècle. Finalement, l'analyse sur le Nord-est de la province, en montrant les hypothèses de conflit sur la frontière avec le Brésil -propres du discours autoritaire d'époque- avant d'analyser la affermissement définitive du tabac dans la zone, à travers du phénomène de subsomption au travail.

Mots-clés : Front Pionnier, Colonisation Processus, Hypothèses de Conflit, Tabac, Subsomption.

\section{Introducción}

Durante la primera mitad del siglo XIX, las tierras del actual territorio de Misiones fueron disputadas entre Paraguay, Brasil y Corrientes. Las arremetidas de los distintos ejércitos por la dominación territorial continuaron hasta la finalización de la Guerra del Paraguay (1865-1870). Durante aquel período, se consolidó la economía de extracción de yerba mate de los yerbales naturales y de madera ley, transportada a través de las pequeñas picadas en el monte hacía los precarios puertos de los dos principales ríos: el Paraná y el Uruguay. La escasa densidad espacial en materia de transporte de aquella época se tradujo en el desarrollo de la navegación fluvial como casi la única alternativa de comunicación a lo largo de toda la región. De esta forma, fue estructurándose el avance del frente extractivo sobre lo que actualmente comprende a la Provincia de Misiones.

No obstante, ya a principios del siglo pasado la morfología del frente fue convirtiéndose en una frontera agropecuaria estable y en proceso de consolidación. La predominancia del frente va a extenderse hasta, aproximadamente, la década del treinta. La estabilidad en los asentamientos poblacionales y el crecimiento de la red de transportes y servicios -a remolque de la producción de perennes- iría transformando el típico espacio de extracción y enclave característico del primer período de explotación del suelo.

Más tarde, empiezan a adquirir mayor relevancia los cultivos anuales de renta como el tabaco y las plantaciones de pino, en detrimento de los perennes más tradicionales como la yerba, el té y el tung. A principio de la década del sesenta, la reforestación de coníferas cobra relevancia a raíz de la instalación de una gran papelera a orillas del Alto Paraná, "Celulosa Puerto Piray", promocionada y explotada por capitales extra-regionales. Finalmente y hasta la actualidad, se establece de manera definitiva el tabaco burley en el Nordeste Provincial, mientras que el pino eliotti predomina sobre las costas del Río Paraná. Así, a orillas del Río Uruguay se consolida la producción tabacalera en el espacio de colonización más reciente de la provincia, con rasgos diferentes respecto a otras áreas como el Sur Provincial o el Alto Paraná. Asimismo, los inicios de esta expansión agraria se enmarcan en el contexto de las hipótesis de conflicto con el Brasil, propias de la última dictadura.

\section{Formación social de fronteras en Misiones}

\section{Avance del frente extractivo y apropiación originaria de la tierra}

Hacia la segunda mitad del siglo, el modo de ocupación y administración del territorio misionero por parte del gobierno correntino, junto a la formalización de la tenencia y reparto de las tierras (que se habían efectuado desde 1830) se constituyen como los procesos 


\section{Papeles de Trabajo $N^{o} 26$ - Diciembre 2013 - ISSN 1852-4508 \\ Centro de Estudios Interdisciplinarios en Etnolingüística y Antropología Socio-Cultural}

fundamentales para comprender el posterior usufructo de la tierra. En un principio, las tierras fueron arrendadas a ganaderos en el sur provincial y luego, en 1860, se subastaron. Fue consolidándose el denominado frente extractivo de colonización que caracterizó y definió el espacio geográfico regional al mismo tiempo que la economía nacional iba insertándose en las relaciones internacionales del capitalismo mundial (Abínzano, 1985).

Según este autor, las características principales del régimen de acumulación regional comprendían una baja inversión (típica de las economías extractivas de enclave de aquella época) relaciones de producción precapitalistas, la expoliación de los recursos de la tierra (yerbales naturales y maderas ley) y su inserción en un sistema de mercado regulado extraregionalmente. De este modo, los empresarios obtenían ganancias extraordinarias a partir de la extracción indiscriminada de materia prima local, industrializándola fuera de la región.

Este proceso, que pudo desarrollarse entre los años 1865 y 1930, gracias al modo de regulación que permitió un usufructo sin control, fue acompañado por el desarrollo de una exigua red de vías de comunicación y pequeños poblados comunicados, esencialmente, a través de los accesos fluviales y sus principales puertos comerciales. Desde el punto de vista social, la aparición de una clase social encargada de dar plataforma a la elite local capacitada para desempeñar roles económicos, políticos, sociales y culturales -como ocurre en las sociedades pioneras donde los actores se ven compelidos a una multiplicidad de tareas que abarcan un espectro muy amplio de locus sociales- se fundamentó sobre las base de la administración de los recursos de la tierra.

Por otra parte, se desarrolló un conjunto de industrias de bajo procesamiento ligadas a la extracción de yerba y madera (molinos, obrajes y aserraderos) que no llegaron a poner en peligro el esquema fundamental orientado a incorporar valor agregado a las materias primas fuera de la provincia. Las verdaderas agroindustrias locales que procuraron competir con las instaladas en Buenos Aires y Rosario surgirían más tarde, como fruto de la colonización agrícola, conformando una nueva clase cuyos intereses responderían, en mayor medida, a la región. De este modo, el proceso de territorialización se sustentó en la explotación de los recursos de la tierra con escaso nivel de procesamiento y sin generación de valor agregado a escala local, traduciéndose este fenómeno en una baja sedentarización y una alta inestabilidad poblacional (Abínzano, 1985).

En el mismo sentido, este frente extractivo formó parte de un modo de explotación regional; un sistema productivo hegemónico que se desarrolló en el Noreste Argentino, gran parte de Paraguay y el Sudeste de Brasil. Como asegura Abínzano: "Una formación socioeconómica espacial en una región que no es la delimitada por un Estado-Nación, sino una región transnacional compartida" (2004: 1). Se trata, entonces, de una gran formación social de fronteras de similares características agronómicas, productivas, sociales y transfronterizas donde el proceso de territorialización adquiere rasgos generales atravesados por especificidades locales, combinándose las relaciones de producción, las fuerzas productivas y los medios de producción regionales con los sistemas culturales específicos de cada Estado-Nación emergente (Trinchero, 2000).

Este sistema productivo presentó en Misiones características asimilables a otros frentes de explotación de tierras vírgenes, sobre la base del trabajo humano en América Latina tales como la producción de caucho en la Amazonia o el quebracho en la provincia del Chaco (Abínzano, 2004). De la misma manera, estas prácticas extractivas de enclave continuaron proporcionándose hasta bien entrado el siglo XX, pese al asiento definitivo de colonos europeos y la adopción de cultivos perennes (yerba mate y té principalmente) en el inicio secular. Incluso, este tipo de usufructo ha persistido, hasta el día de hoy, en algunas áreas del Alto Uruguay, lo cual indica -una vez más- que la combinación de las formas de producción se establece a partir de la obtención de ganancias extraordinarias, refuncionalizándose viejas prácticas productivas de acuerdo a los requerimientos del capital extractivo.

Por su parte, se hizo necesario controlar, de manera efectiva, el espacio interno por parte del Estado Argentino a través del ejercicio de territorialidad "fronteras adentro". Para el caso de Misiones, Territorio Nacional hasta 1881, la puesta en valor definitiva del espacio a través de la colonización efectiva no se produciría hasta el siglo XX. De esta manera, la consolidación del 


\title{
Papeles de Trabajo $N^{\circ} 26$ - Diciembre 2013 - ISSN 1852-4508 \\ Centro de Estudios Interdisciplinarios en Etnolingüística y Antropología Socio-Cultural
}

aparato productivo orientado hacia la explotación de materias primas -a partir del asentamiento de colonos- se combinó con la hipótesis de conflicto "fronteras afuera", encontrándose a una distancia de Paraguay y Brasil de, apenas, 300 kilómetros.

Los límites internacionales no terminaron de definirse hasta finales del siglo XIX. Si bien los pleitos con el Paraguay habían sido saldados definitivamente al término de la guerra, utilizando como división a la línea imaginaria que atraviesa las áreas más profundas del cauce del río Paraná, los problemas limítrofes con el Brasil no fueron zanjados hasta 1895 con el laudo internacional del presidente de Estados Unidos. Este último resolvió que Brasil se quedara con, aproximadamente, $30.000 \mathrm{~km}^{2}$ en disputa, fijándose el límite sobre los ríos Iguazú, San Antonio, Pepirí-Guazú y Uruguay (Abínzano, 1985).

En el lapso comprendido desde el comienzo de la Guerra de la Triple Alianza (1865) hasta la federalización de Misiones (1881) las tierras del actual territorio misionero eran, casi en su totalidad, fiscales. Poco antes de la federalización, Corrientes decidió la enajenación de la totalidad de las tierras. Según Abínzano (1985), este hecho produjo algunas variaciones dentro del frente (importante para entonces en volumen de operaciones) consistente en la vinculación entre los empresarios y pioneros, y las nuevas personas jurídicas propietarias de las tierras que, básicamente, eran propietarios absentistas que habían invertido en esas tierras de forma especulativa. Tiempo antes de sancionarse la ley de federalización de Misiones, Corrientes decidió entregar a la Nación la jurisdicción de esas tierras, no así su propiedad. En este sentido, Ziman y Scherer afirman:

\begin{abstract}
"En vista de esta situación y de la pronta y segura salida de Misiones de la jurisdicción correntina para pasar a la nacional como territorio nacional, el Gobernador de Corrientes Antonio Gallino, con el propósito de entregar al Gobierno Nacional solamente la jurisdicción del territorio de Misiones pero sin la propiedad, logró que la legislación de Corrientes ya el día 12 de junio de 1881 sancionara la Ley de Tierras por la cual se autorizó a la Gobernación de Corrientes a enajenar todas las tierras de Misiones a razón de lotes de 25 leguas cuadradas, o sea a razón de lotes de 67.500 hectáreas” (1976: 89).
\end{abstract}

Es de este modo como se realiza la venta de más de dos millones de hectáreas sobre la base de mapas rudimentarios e inexactos, favoreciendo a grandes empresas de origen nacional y extranjero, permaneciendo gran parte del territorio misionero en manos privadas. A su vez, la no elaboración de las mensuras excluyó de la venta a unos $6.990 \mathrm{~km}^{2}$ de los $29.801 \mathrm{~km}^{2}$ totales. Un tiempo después, el gobierno del Territorio Nacional rescató tierras que no habían cumplido el requisito de realizar las mensuras obligatorias durante el plazo que les había sido estipulado. De todas maneras, la adjudicación de alrededor de un $80 \%$ de las tierras disponibles en sólo algunas pocas manos pone de relieve el nivel extremo de concentración originaria de la tierra en la provincia de Misiones (Abínzano, 1985; Kostlin, 2003). ${ }^{3}$

Es así como casi la totalidad del territorio misionero fue absorbido por muy pocos propietarios. Frente a este panorama, el naciente gobierno provincial intentó recuperar algunas porciones de tierra con el objetivo posterior de colonizarlas. De esta manera, se vería enfrentado a un vasto territorio privado y sin explotar por el que tendría que comenzar a ejercer su control sorteando diversas limitaciones y, al mismo tiempo, teniendo que ponerlo en producción. Siguiendo a Bartolomé:

\begin{abstract}
"Cuando en diciembre de 1881 se creó el Territorio Nacional de Misiones, las nuevas autoridades se encontraron con que gran parte del territorio había pasado a manos privadas, y para peor, de propietarios ausentistas. Empero, el mismo apresuramiento del gobierno correntino al realizar las ventas permitió recuperar un buen porcentaje de esas tierras.
\end{abstract}

\footnotetext{
${ }^{3}$ Kostlin remarca que "Existen según las fuentes consultadas diferencias en relación a la cantidad de hectáreas vendidas y número de adquirientes. A saber, Bolsi (1976) señala que la venta de 2.101 .936 se efectuó a 29 compradores, mientras que Eidt (1971, en Abínzano, 1985) señala que se trató de 38 adquirientes de 2.025.000 hectáreas. A nuestro entender, lo relevante está en la magnitud de tierras que de un momento a otro fueron concentradas por manos privadas, sobre todo ausentistas" (2003: 21).
} 


\title{
Papeles de Trabajo $N^{\circ} 26$ - Diciembre 2013 - ISSN 1852-4508 \\ Centro de Estudios Interdisciplinarios en Etnolingüistica y Antropología Socio-Cultural
}

\begin{abstract}
Algunas pasaron nuevamente al fisco por no haber cumplido los adquirientes con la estipulación de practicar la mensura dentro de un plazo de diez años a partir de la venta. Pero el principal factor que permitió recuperar grandes extensiones fue la errónea mensura de las tierras vendidas; error que devolvió al fisco una ancha faja de tierras a lo largo del dorsal central del territorio. De esta manera, pudo encararse un plan de colonización en tierras públicas, que comenzó por la zona de campo y posteriormente se extendió a las Sierras Centrales" (1982: 7).
\end{abstract}

A ello fueron sumándosele ciertos dispositivos legales que facilitaron la puesta en producción del territorio a través del sistema de colonización, como la Ley de Inmigración y Colonización de 1976 y la Ley de Venta de Tierras Fiscales de 1882 que vino a normativizar la enajenación de las tierras públicas. De este modo, se crearon las condiciones para sistematizar el proceso de poblamiento efectivo a nivel provincial, que tendría a los colonos y sus plantaciones de perennes como la columna vertebral del agro misionero.

\section{Proceso organizado de poblamiento en el Territorio Nacional}

La existencia del Territorio Nacional de Misiones se dio desde 1881 hasta 1953 , año de la provincialización. Puede situarse al comienzo efectivo del proceso de colonización planificada a partir de 1897, momento en el cual se materializa la primera experiencia exitosa en el área de Apóstoles, en el sur provincial. Seguidamente, se desarrolla un acelerado crecimiento poblacional que se extiende por el sudeste, así como por la dorsal serrana que había permanecido como tierra fiscal gracias al error de mensura. En las décadas posteriores fueron abriéndose picadas y colonias a lo largo y ancho del monte mientras que la agricultura comercial fue ganando peso en detrimento de la de subsistencia, a la vez que fueron expandiéndose los pequeños centros urbanos que brindaban servicios públicos y comerciales a una población en rápido incremento (García, 2010).

Respecto a la expansión de la frontera agropecuaria, entre los años 1895 y 1920 la superficie cultivada casi se triplicó, pasando de 13.200 a más de 36.000 hectáreas (Bolsi, 1982). Por su parte, la población creció de 33.163 a 63.176 habitantes, con un crecimiento anual medio de 2,6 \%o (García, 2004). En muchos casos, los pioneros ocupaban la tierra "de hecho" y se realizaba la mensura tras la ocupación. De todos modos, la colonización se planificaba desde el Estado y existían colonias tanto públicas como privadas. En este sentido, la Ley Avellaneda "establecía dos sistemas de colonización: 1) la directa a cargo del Estado; 2) la indirecta mediante entrega de concesiones de tierras a particulares quienes bajo ciertas condiciones se encargarían de la instalación de los centros" (Maeder y Gutiérrez, 1995: 118).

Si se las compara en término de costos, las colonias públicas eran la mejor opción para el inmigrante. Sin embargo, el patrón de asentamiento seleccionado (el damero) no era el más apto para sitios con pendientes pronunciadas $-\mathrm{y}$, por ende, con áreas desigualmente drenadascaracterísticas edáficas heterogéneas y afloramientos rocosos. Por lo general, las colonias privadas ofrecían, además, asesoramiento técnico y un patrón de asentamiento lineal, con lotes en forma de franja que habían sido imitados de la experiencia colonizadora del sur brasileño (Bartolomé, 1982). ${ }^{4}$

El tamaño de las parcelas se fijó entre las 25 y 100 has, orientándose la política de colonización hacia la agricultura familiar. Los nuevos colonos fueron, principalmente, inmigrantes europeos que no encontraron tierras disponibles en la Pampa Húmeda, así como brasileros, paraguayos y correntinos que tampoco accedieron a la tierra en sus lugares de origen. No obstante, existieron serias deficiencias organizativas por parte del Estado. Según Abínzano (1985), no se titularizaron gran cantidad de parcelas, lo cual originó en los agricultores, durante largo tiempo

\footnotetext{
${ }^{4}$ Las colonias que se produjeron en el sur y la dorsal central del territorio misiones fueron con auspicio estatal, mientras que las que se instalaron en la zona noroeste (Eldorado, Puerto Rico y Montecarlo) fueron creadas y organizadas fundamentalmente por compañías privadas de colonización (Bartolomé, 1974; García, 2004).
} 


\section{Papeles de Trabajo $N^{o} 26$ - Diciembre 2013 - ISSN 1852-4508 \\ Centro de Estudios Interdisciplinarios en Etnolingüística y Antropología Socio-Cultural}

una situación de indefinición en términos legales. Este hecho significó para Misiones la presencia de numerosa población en calidad de ocupantes de tierras fiscales.

Más allá de ciertas contradicciones, el modelo de colonización resultó exitoso ya que los objetivos de poblamiento y puesta en producción del territorio fueron alcanzados. Bartolomé (1974) sostiene que la aplicación de una política de tierras públicas que posibilitó el acceso a la propiedad de la tierra, sumado a los bajos impuestos y a la presencia de un cultivo rentable como la yerba mate, se constituyeron en factores que permitieron obtener estos buenos resultados.

Específicamente, para el caso del Alto Uruguay y el Nordeste Provincial el proceso de colonización se vio motivado, en gran parte, a partir de una funcionalidad instrumental de acuerdo al ejercicio de territorialidad por parte del Estado Nacional. Los recientes conflictos limítrofes que se habían ocasionado con Brasil, el escaso poblamiento del área y la "porosidad" de la frontera por la falta de control, estimularon discursos y prácticas tendientes a reforzar la vigilancia sobre esta formación de fronteras. Ante este escenario, la finalidad práctica del poblamiento en el Nordeste Provincial estuvo basada en consolidar el poder territorial por parte del Estado, a través de la expansión de la frontera agropecuaria.

A su vez, la existencia de gran cantidad de tierras fiscales disponibles hizo posible también este tipo de desarrollo. Básicamente, la colonización del espacio misionero se dividió entre los emprendimientos públicos y privados, como fue señalado más arriba. Para acceder a las tierras de las colonias privadas tenía que poder contarse con cierto nivel de capitalización, lo que representaba un límite para una gran cantidad de inmigrantes de escasos recursos. Es así como el proceso de ocupación se dinamiza en la dorsal central y el Nordeste Provincial sobre las parcelas fiscales (Bartolomé, 2000).

Durante la primera fase de colonización - esto es, hasta 1914- se observan altos índices de propietarios mientras que, a partir de aquella fecha, existe un gran número de ejemplos que se corresponden con la categoría "otras formas" (siendo aquellas que no están en propiedad ni arriendo). Ello estaría indicando las crecientes dificultades encontradas por los colonos, al momento de adquirir las tierras. Las cifras correspondientes a esta categoría para el año 1920 llegan al 50,5\% de las explotaciones, elevándose al 61,1\% en 1937 (Palomares, 1975 en Kostlin, 2003). ${ }^{5}$

De este modo, las porciones de tierras fiscales aún no colonizadas actúan como válvula de escape ante la presión de los inmigrantes que no encuentran espacio disponible en las colonias pertenecientes al primer período. Es así como entre 1916 y 1921 se va poblando el espacio físcal de las Sierras Centrales y el Nordeste Provincial, siendo Alem, Campo Grande y San Pedro los lugares de asiento. Durante esta etapa, el acceso es gratuito y existe ayuda pública para la instalación, con un tamaño promedio de parcela de 25 has. Este sistema se vería implementado hasta aproximadamente el año 1940, momento en el cual comienza a transformarse la visión estatal sobre el espacio productivo. Este modelo, basado en el poblamiento de pequeños colonos con cultivos de perennes (yerba mate, luego el tung y el té) se reorienta hacia el sector agroindustrial de reforestación de pino y eucaliptus a gran escala hacia 1960, apoyándose sobre una nueva división espacial de la producción nacional.

Sintéticamente, el sistema colonizador de la tierra arrojaría como resultado una estructura agraria dividida en dos tipos de explotación: el minifundio y el latifundio (Abínzano, 1985). La combinación de pequeños colonos de frontera con medianos plantadores y grandes latifundios forestales conformaría, entonces, una compleja estructura agraria con gran cantidad de predios (con un tamaño de parcela de entre 25 y 100 has), pero más del 60 por ciento de la tierra en manos de latifundistas (Reboratti, 1979). De este modo, la colonización suscitaría la ocupación

\footnotetext{
5 "La existencia de esta situación en el régimen de tenencia de la tierra se observa precisamente en aquellos departamentos en que no hubo asentamientos de colonos de acuerdo a un proyecto de colonización específico, sino que fueron objeto de constantes migraciones de personas". En relación a los departamentos que presentan esta categoría, señala que son aquellos en los que existe el "predominio económico del monte", con lo cual se deja ver la existencia de un fenómeno de ocupación de tierras fiscales a partir de la actividad extractiva (Palomares, 1975: 19 en Kostlin, 2003).
} 


\section{Papeles de Trabajo $N^{o} 26$ - Diciembre 2013 - ISSN 1852-4508 \\ Centro de Estudios Interdisciplinarios en Etnolingüistica y Antropología Socio-Cultural}

del espacio misionero y el avance de la frontera agraria sobre tierras fiscales, mientras que la apropiación originaria de la tierra determinaría la existencia de la gran propiedad privada. El cultivo por excelencia sería el de yerba mate, afectado de manera recurrente por crisis de sobreproducción.

\section{Puesta en producción del espacio provincial}

La historia de la provincia es la historia de la extracción de madera y de la expansión de la frontera agraria, con la yerba mate como el cultivo iniciático, hasta la introducción de tung, té, tabaco y cítricos. La actividad maderera fue la primera forma de expansión del frente extractivo en Misiones, junto a la explotación de los yerbales naturales. Estas compañías obrajeras, tras la extracción selectiva de maderas ley (generalmente se trataba de pequeños empresarios que explotaban grandes áreas de bosques arrendadas al Estado o a particulares) abandonaban las tierras dejando senderos (picadas) que atravesaban la espesa selva y se dirigían desde las áreas de explotación hasta los aserraderos donde se procesaba la madera. A través de esas "picadas" fueron penetrando los "colonos", accediendo a las parcelas que limpiaban mediante roza y tala. En estos lotes se comenzaban a plantar cultivos anuales de rápido retorno económico, como el tabaco, para al cabo de unos años, ser reemplazados por yerba, té o tung, dependiendo de la coyuntura económica (Reboratti, 1983).

Desde principios del siglo pasado hasta alrededor del año 1930, la producción giraría en torno al cultivo comercial de la yerba mate que, en un principio, se basaba en la recolección de las matas silvestres. A partir de la década del treinta, la yerba mate ingresa en una crisis de sobreproducción debido a las limitaciones de demanda del mercado interno, la importación desde Paraguay y Brasil y la falta de regulación de la producción. La prohibición de plantar nuevos yerbatales - política implementada a raíz de la crisis- y la expansión agraria producida por la masa de migrantes, trajo aparejada la implementación de un nuevo cultivo hacia fines de ese decenio, el tung (Rofman, 1983).

Este último cultivo predominó durante la década de 1940 y hasta la mitad de 1950, cuando el mercado mundial de las oleaginosas y la tecnología dentro de esta industria empezó a limitar la producción, aun cuando no pueda hablarse, estrictamente, de una crisis. En esta época se rehabilita la plantación de nuevos yerbatales dada la presión del mercado interno, la cual conduce a que se triplique el área cultivada y devenga en una nueva crisis de sobreproducción. Para esta segunda crisis de la yerba mate se implementa otro cultivo, el té, ampliamente beneficiado por las políticas proteccionistas aplicadas a la importación en el sector.

A partir de la provincialización de Misiones, en 1953 comienzan a desarrollarse diversos estímulos orientados a promover la agroindustria del papel celulosa. Se van conformando nuevos aserraderos de pequeña escala a partir de establecimientos familiares que obtenían la madera a través del desmonte en sus parcelas, o bien, en los terrenos vecinos de pequeños productores agrícolas (Freaza, 2000). Por aquellos años se instalan en la provincia, especialmente en el Alto Paraná, diferentes papeleras a la vera del río, promoviendo el desarrollo forestal sobre la base del incremento en las superficies de bosques implantados y reforestados, principalmente con pino eliotti (especie resinosa que se utiliza para la industria del papel y la celulosa).

Por otra parte, a mediados de este mismo decenio se volvió a prohibir la plantación de nuevos yerbatales, el precio del tung se encontraba muy bajo mientras que, tanto el té como el tabaco, mantenían sus precios aunque en forma irregular. Es en éste momento cuando se introducen los cítricos y las esencias. Sin embargo, estas producciones se desarrollaron, espacialmente, de manera muy limitada. En función de lo hasta aquí expuesto, cabe señalar que las producciones misioneras -a excepción de la industria forestal- han estado estrechamente relacionadas con las fluctuaciones del mercado interno y externo.

Los últimos cuatro decenios han traído aparejada la concentración de las principales actividades dentro de la agricultura perenne, principalmente el té y la yerba mate, a través del acopio y procesamiento de estos cultivos. El incremento en la producción de yerba mate, durante los 
últimos dos decenios, se debió, esencialmente, al aumento de la productividad por hectárea. El cambio más importante fue el producido en 1991, debido a la desregulación de la actividad conforme al nuevo esquema de libre competencia, teniendo como principal consecuencia el notable incremento de la producción, pero no así del consumo, lo que determinó una caída en el precio del producto primario. En el año 2002 se crea el Instituto Nacional de la Yerba Mate (INYM) ${ }^{6}$ con el objeto de regular los precios, elevando notablemente los valores de la hoja verde y la hoja canchada. Sin embargo, no se ha logrado contrarrestar el proceso histórico de concentración, agudizado durante la década anterior, que proporcionó una estructura oligopsónica que se erige a partir de los molinos y secaderos que industrializan la materia prima, y los supermercados que comercializan el producto final.

De manera similar sucedió en los mercados del té y el tabaco, donde la fijación de los precios se rige desde los acopiadores e industrializadores del producto en bruto, situación que redundó en la escasa viabilidad del pequeño productor que practica de estos cultivos. En 1992 se desregula la actividad tealera eliminando el "precio garantía" del brote al comienzo de la campaña mientras que, para del caso del tabaco, existe un "sobreprecio" a la hora de comercializar la cosecha, el Fondo Especial del Tabaco (FET) que garantiza las ganancias de acopiadores y multinacionales (Freaza, 2000; García, 2010).

En cuanto a la explotación forestal, puede verificarse un notable crecimiento del sector manufacturero gracias a un heterogéneo paquete de políticas que comenzaron a aplicarse desde mediados de los años setenta. Estos estímulos produjeron el incremento de las superficies reforestadas así como la concentración en el sector de procesamiento de las pastas celulósicas y de papel. En el año 1977 se promulgó la Ley de Estímulos Fiscales para la Forestación n ${ }^{\circ}$ 21.695 que estableció el crédito fiscal a la actividad con vigencia hasta 1991. Años Más tarde en 1995- se elaboró el Plan Nacional de Desarrollo Forestal con el propósito de fortalecer al sector. Por último, en 1999 se sancionó la Ley Nacional 25.080 de Inversiones para Bosques Cultivados, que contempla una política de incentivos a la foresto-industria con subsidios para plantaciones hasta el 2009, estabilidad fiscal de 30 y hasta 50 años para los proyectos forestoindustriales, además de beneficios impositivos de la jurisdicción nacional, provincial y municipal (Kostlin, 2003).

Todo este paquete de políticas se ha traducido en un gran estímulo para el crecimiento de la industria forestal, que se halla localizada, preferencialmente, en la Cuenca Alta del Río Paraná (Eldorado, Libertad, Piray, Puerto Esperanza y Montecarlo) y en el Nordeste Provincial (San Vicente y San Pedro). En el Mapa 1 puede observarse el polígono forestal, el cual refiere a espacios que ya han sido desmontados y reforestados con especies foráneas, principalmente coníferas. Son grandes extensiones de tierras dedicadas al monocultivo de esta división de plantas, predominando el pino eliotti.

\footnotetext{
${ }^{6}$ Esta institución vino a cumplir el rol de fijación de precios que había tenido anteriormente la Comisión Reguladora de la Yerba Mate (CRYM), que se había desenvuelto entre 1935 y 1991 (Rau, 2008).
} 
Mapa 1. Polígono de desarrollo forestal en el Alto Paraná y en el Nordeste Provincial.

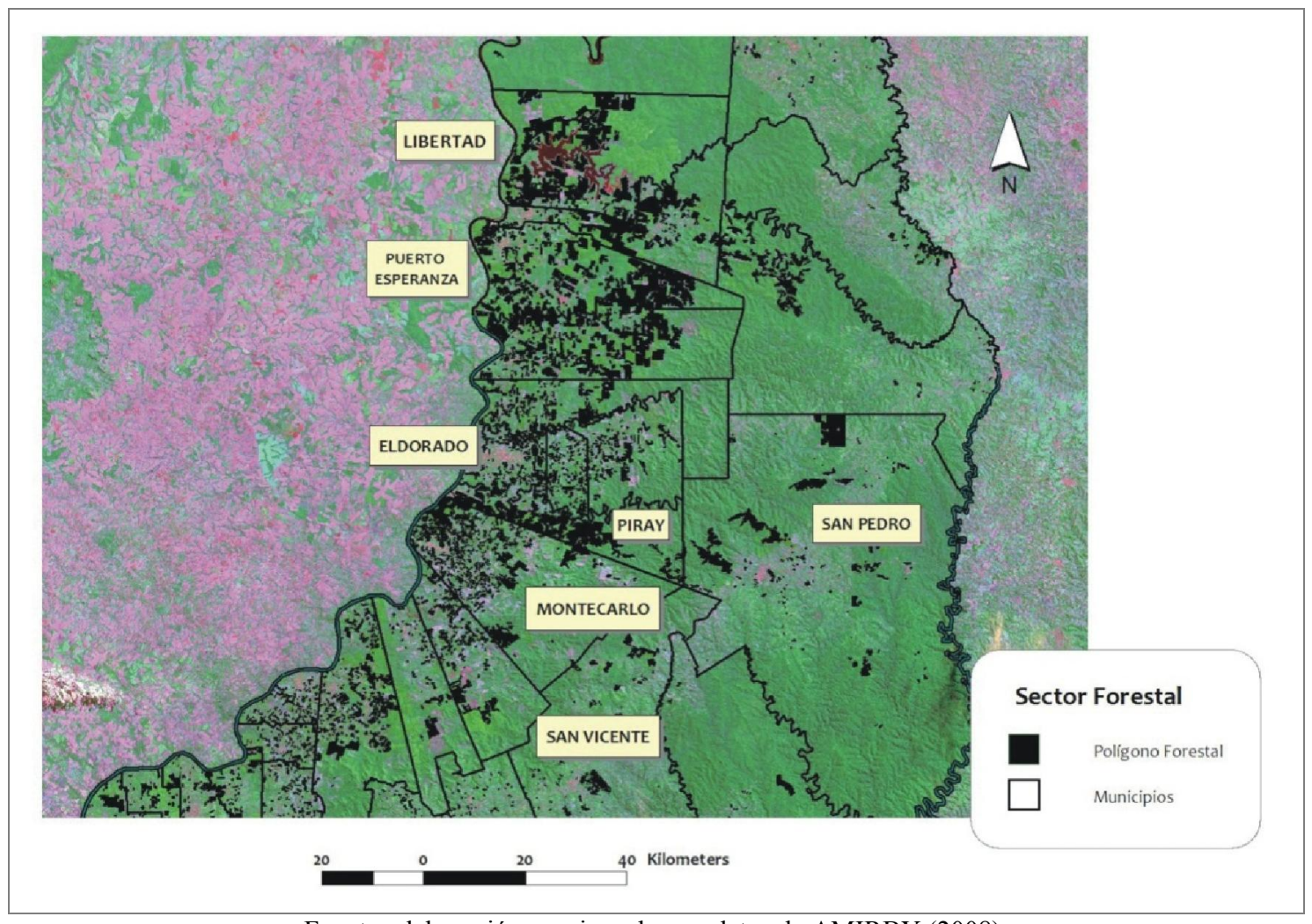

Fuente: elaboración propia en base a datos de AMIRBY (2008).

Nota: Imagen Landsat 2008 WGS 1984.

\section{Expansión de la frontera productiva en el Nordeste Provincial}

\section{Poblamiento no planificado e hipótesis de conflicto}

Una vez concluida la colonización oficial alrededor de la década de 1940, las tierras fiscales del Nordeste Misionero - que no habían sido objeto de las políticas de colonización planificada- se convierten en asentamiento de la población rural excedente de los estados del sur de Brasil y de las colonias más antiguas del sur y centro de la provincia (Schiavoni, 1999). Para el decenio que va de 1950 a 1960, la frontera agropecuaria del noroeste de Río Grande do Sul se encuentra casi totalmente saturada en su capacidad espacial, estableciéndose como una frontera en extinción. El oeste del estado de Santa Catarina se constituye como una frontera estable consolidada en los setenta, mientras que el sudoeste del estado de Paraná se convierte en una frontera explosiva entre 1950 y 1970. En ese contexto regional, la provincia de Misiones aparece como una frontera indecisa, sin desarrollo dinámico: "El este, a pesar de poseer una gran reserva de tierras, no presenta un desarrollo fronterizo dinámico. La frontera avanza mediante la instalación de pequeños colonos, posiblemente ilegales, mientras que en el otro extremo se mantiene la presencia de grandes latifundios forestales" (Reboratti, 1979: 21).

En el Mapa 2 pueden identificarse las principales corrientes migratorias en la formación social del Alto Paraná y Uruguay durante el siglo pasado, además del pleno de ocupación (considerándose como más del $75 \%$ del espacio comprendido en cada uno de los estados de segundo orden). El agotamiento de las tierras en Río Grande do Sul se da para 1960, alcanzando casi un $100 \%$ de ocupación. Es entre aquel año y 1970 que el Nordeste Misionero empieza a recibir población brasileña excedente, así como de las colonias del centro y sur de Misiones. Por su parte, el noroeste de Misiones no recibe población del Paraguay del mismo modo ya que, para aquella época, el Alto Paraná no se encontraba tan despoblado como el Alto Uruguay. 
Asimismo, esta situación sirve de refugio para muchas comunidades Mbyá Guaraníes del Nordeste Provincial.

\section{Mapa 2. Principales corrientes migratorias en la formación social del Alto Paraná-Uruguay (1950-1970).}

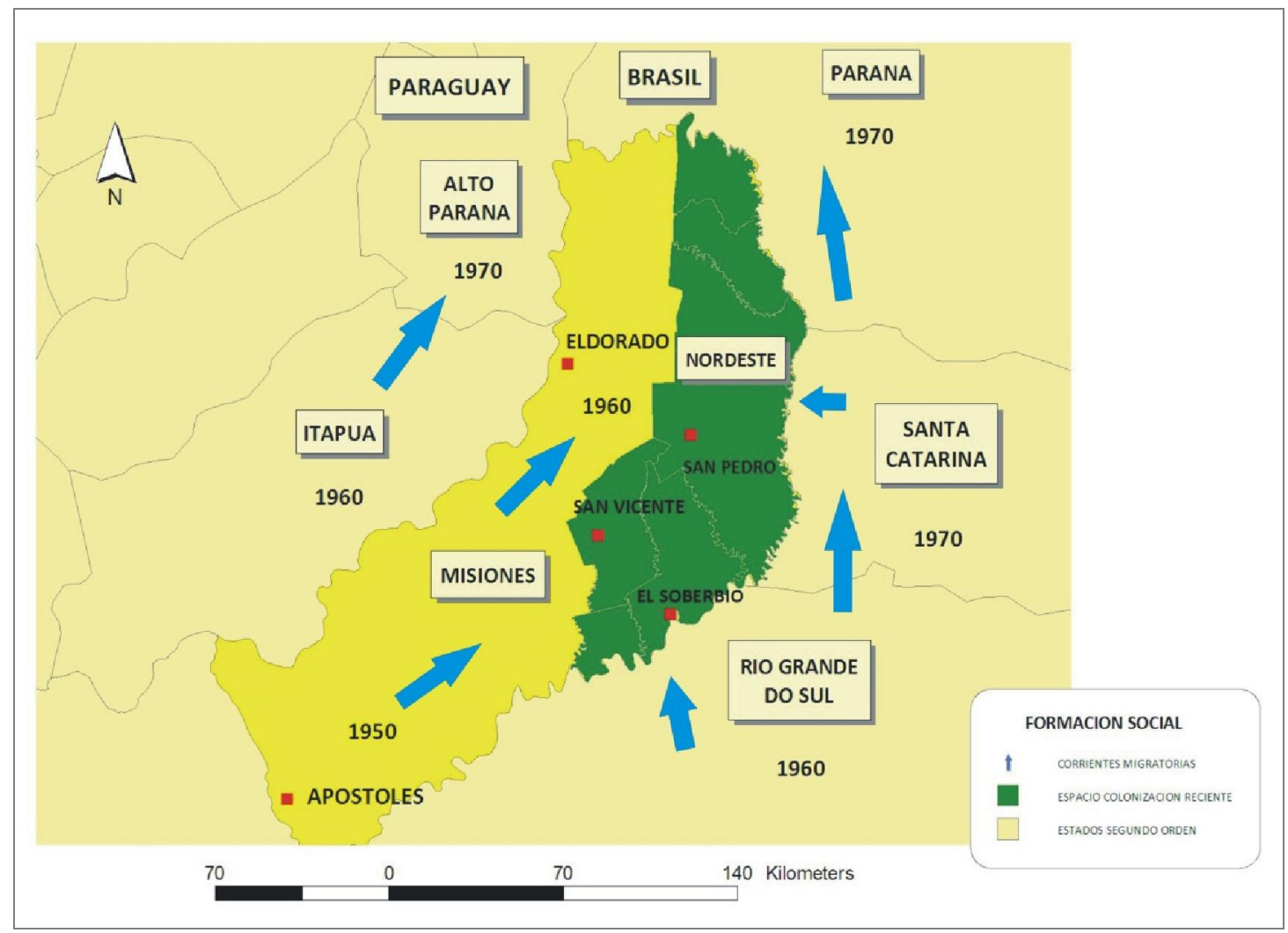

Fuente: elaboración propia en base a Reboratti (1979).

Nota: los años muestran el pleno de ocupación (más del 75\% del espacio comprendido).

Con este escenario, la ocupación no planificada del territorio misionero se asocia a las hipótesis de conflicto que se conciben sobre las fronteras nacionales. En la segunda mitad del siglo XX, los gobiernos de corte populista y desarrollista - principalmente los regímenes militaresconvierten a las regiones periféricas de frontera, con escasa integración al espacio económico central, poca población y baja densidad en infraestructura, en potenciales "frentes" de guerra. De este modo, las fronteras estatales pasan a desempeñar un papel importante en la producción de discursos nacionalistas y chauvinistas, reflejando el ejercicio de territorialidad por parte del Estado antes que conflictos reales con las naciones vecinas (Foucher, 1991 en Schiavoni, 1999). En este sentido, los dispositivos de territorialidad estatal se traducen en el avance de la frontera agropecuaria y la consolidación de la frontera nacional.

Como afirma Schiavoni:

"Cuando Las tierras fiscales escasamente pobladas de los departamentos de 25 de Mayo, Guaraní, San Pedro y General Belgrano (nordeste del territorio) se definieron en la década de 1970 como Área de Frontera Bernardo de Irigoyen. En ese año se promulga la Ley Nacional $\mathrm{n}^{\circ} 18.575$, que contiene normas para el desarrollo e integración de las zonas y áreas de frontera de Nación. Por un decreto nacional de 1972 se establece como área de frontera una zona que comprende a los departamentos provinciales San Pedro y General 


\title{
Papeles de Trabajo $N^{\circ} 26$ - Diciembre 2013 - ISSN 1852-4508 \\ Centro de Estudios Interdisciplinarios en Etnolingüística y Antropología Socio-Cultural
}

\begin{abstract}
Belgrano; en 1980 son anexados 25 de Mayo, Guaraní y parte de Iguazú. Definida oficialmente por la falta de desarrollo, carencia de infraestructura de obras y servicios, vacío poblacional, falta de integración física y espiritual con el resto de la nación, y por la irradiación e infiltración de los países limítrofes, la frontera comienza a vislumbrarse como un espacio con destino forestal" (1999: 4).
\end{abstract}

Detrás de estos programas de ordenamiento territorial existe la intención, por parte de las autoridades nacionales de facto, de promover el desarrollo del capital forestal al ritmo de la sanción de leyes que estimulen la industria. Como ya se mencionó más arriba, en el año 1977 se promulga la Ley de Estímulos Fiscales para la Forestación. Es así como el poblamiento y la ocupación agrícola se asocian al "peligro" de penetración brasileña. Un informe oficial de la provincia del año 1975 asegura:

"El área fronteriza continúa siendo un sector con un gran vacío poblacional [...] puede decirse que sigue constituyendo un despoblado argentino con tendencia a convertirse en un poblado brasileño [...] el riesgo que significa un poblamiento extranjero limítrofe lindante a su país de origen es el de que genera la extensión de una ecología humana reflejada en el idioma, costumbres, tradiciones, que difiere de lo que podría denominarse idiosincrasia argentina".

La población extranjera, de brasileños y paraguayos, se localiza predominantemente en áreas rurales, siendo que "mientras el grupo paraguayo se dedica en su gran mayoría a las actividades en el obraje, el brasileño prefiere la agricultura" (Misiones, 1975). La actividad forestal (el obraje) no supone arraigo y ocupación del suelo; en cambio la inmigración agrícola brasileña implica un grado mayor de apropiación de la tierra, y se convierte así en el blanco de esta política de defensa de la soberanía nacional (Schiavoni, 1999).

En 1977 se publican los Lineamientos para la Formulación de un Plan de Desarrollo del Área Bernardo de Irigoyen. La frontera con Brasil se define como área dura debido a sus problemas de seguridad. De esta manera, se presenta una estrategia de "esterilización de amplios sectores de la frontera mediante la definición de una política de uso del suelo con poca absorción de mano de obra [...] unida a una efectiva política policial de cuidado de la frontera" (Misiones, 1977 en Schiavoni, 1999). Poco tiempo después se realizan algunos programas de colonización, como el Plan Andresito ${ }^{7}$ y unas pocas obras de infraestructura (como el puente construido en la localidad de El Soberbio que cruza el arroyo homónimo en dirección norte que se puede ver en la Imagen 1).

En una entrevista a un referente de la localidad de El Soberbio, éste afirmaba:

"A finales de los setenta los militares, con su teoría de la guerra con Brasil, construyeron este enorme puente de hormigón armado de 200 metros de largo y un ancho por el que podian pasar tanques, siempre pensando en el conflicto con el país vecino y la defensa de la frontera nacional" (Nota de campo del 24 de Agosto de 2011).

El tipo de desarrollo territorial que se pensaba por aquellos años, sin integración regional y con orientación hacia la industria forestal, priorizó la construcción de un puente de 202 metros de largo en contraposición con la posibilidad de integrar económicamente esta área con el sur brasilero, a través de un puente internacional con la localidad de Porto Soberbo (que hubiese demandado unos 420 metros de longitud aproximadamente).

Imagen 1. Puente que comunica la localidad de EI Soberbio con el norte del municipio homónimo.

\footnotetext{
${ }^{7}$ Este Plan de ocupación espacial de implementa a partir del año 1979 con el objeto de ocupar unas 64.000 has en el departamento de General Belgrano, con parcelas de entre 100 y 130 has para productores capitalizados tipo farmer con nivel de educación y capacidad económica superior al promedio misionero (Freaza, 2000).
} 


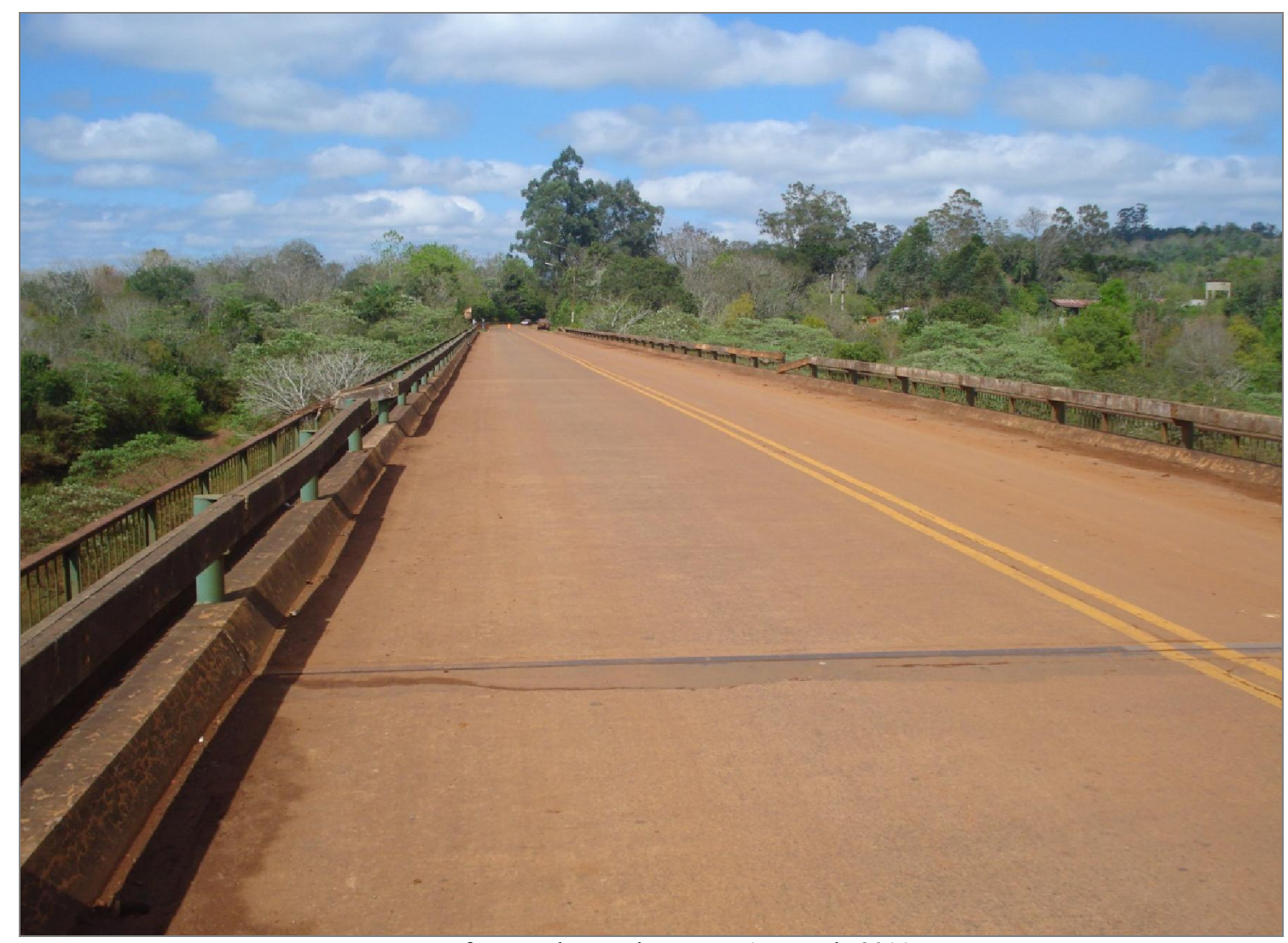

Fotografía tomada por el autor en Agosto de 2011.

Justamente, en esa misma época, el Estado Brasilero promovió activamente la colonización del territorio amazónico a partir de la continua con la puesta en valor de diferentes áreas productivas. Para el caso misionero, el avance de la frontera agropecuaria se desarrolló en paralelo con las hipótesis de conflicto con Brasil, sobredimensionando un fenómeno propio de una formación social de fronteras, la migración desde un país limítrofe, y ocultando la problemática de las poblaciones sin acceso a la tierra del sur y centro provincial. Asimismo, se estimuló la colonización sobre la base de actividades forestales o agricultura familiar capitalizada tipo farmer, proceso que no se vio acompañado por la construcción de un aparato infraestructural que mejorara los niveles de accesibilidad regionales.

De todos modos, la principal vía de poblamiento siguió constituyéndose por la ocupación de tierras fiscales sobre la Dorsal Central de la provincia, como en el caso de la cuña fiscal del municipio de San Vicente que manifestó un acelerado crecimiento en los veinte años que van entre 1960 y 1980, gracias a la actividad maderera y la agricultura (Reboratti, 1981). ${ }^{8}$ De igual manera - pero sin el mismo dinamismo- las tierras privadas a orillas del río Uruguay fueron ocupándose por colonos del sur provincial, a raíz de los proceso de minifundización desarrollados en esta área, y del estado brasilero de Rio Grande do Sul, que durante esos años vivió una explosión demográfica, con la consecuente expulsión de población. ${ }^{9}$ En este sentido,

\footnotetext{
${ }^{8}$ Este mismo autor señala que en el municipio de San Vicente para el año 1980 el $44 \%$ de la población era inmigrante, de los cuales un $64 \%$ provenía de los departamentos del sur provincial y un $24 \%$ eran extranjeros. Asimismo, a partir de una estructura demográfica joven, el segmento etario que va de los 10 a 19 años se componía de un $75 \%$ de sureños y apenas el 1\% de extranjeros (Reboratti, 1981).

${ }^{9}$ En el noroeste del estado de Río Grande do Sul la velocidad de desplazamiento de la frontera de asentamiento estuvo influida por la difusión de cultivos anuales y la cría de porcinos, lo que ha presionado sobre los recursos disponibles. En la década de 1970, a ello se sumó el avance de sistemas empresariales de cultivo, basados en la combinación de trigo y soja, que desplazaron a numerosos pequeños productores. Ese contexto propició y aceleró la emigración hacia áreas menos densas, ubicadas en estados de colonización más reciente como Mato Grosso do Sul.
} 


\title{
Papeles de Trabajo $N^{o} 26$ - Diciembre 2013 - ISSN 1852-4508 \\ Centro de Estudios Interdisciplinarios en Etnolingüistica y Antropología Socio-Cultural
}

el poblamiento no planificado del nordeste de la provincia durante estas dos décadas y hasta 1990 fue impulsado, principalmente, por pequeños productores sin capital que aprovecharon las facilidades de acceso a las tierras públicas. De manera más reciente, se integraron al complejo agroindustrial tabacalero que comenzó a desarrollarse en la zona a partir del decenio de 1980 a través del denominado boom del burley (Schiavoni, 1995a).

\section{Después de la transición: la consolidación del tabaco}

La expansión y afianzamiento de la frontera agropecuaria en el Nordeste Provincial se verificó en la transición desde un modelo de explotación forestal extractivo de madera nativa hacia un esquema de usufructo ganadero y agrícola durante la segunda parte del siglo XX. A su vez, los sistemas agrarios pertenecientes a la colonización no planificada descripta se corresponden con la constitución de un tipo de agricultura familiar específico. Sobre la base de la pequeña explotación, a través de la especialización tabacalera, se observa cierto grado de diversificación con escasa orientación al mercado (ganadería, hortalizas, poroto, maíz, mandioca y en algunos casos yerba y reforestación). Estos rasgos se contraponen del patrón clásico de capitalización mediante la implantación de perennes, el tipo colono (Schiavoni et al, 2006; Diez, 2009).

Un análisis precursor sobre este proceso fue planteado por Dominguez, quien sostenía que la trayectoria típica del agro misionero de ocupante a colono no se había desarrollado de la misma manera en el Nordeste Provincial a raíz de la dinámica que imponía el complejo tabacalero. ${ }^{10} \mathrm{La}$ tipología rural construida por la autora permite diferenciar las trayectorias clásicas -de ocupante a colono- analizadas por Bartolomé (1974) y Schiavoni (1995b), de acuerdo al nuevo modelo de explotación emergente a partir de la especialización tabacalera. Allí se establece una categoría social que se reproduce con el avance de la frontera del tabaco, de ocupante a plantador especializado en burley (García, 2010).

Específicamente, en el Alto Uruguay, se propició una especialización productiva sobre la base del burley que transformó el modelo tabacalero a partir de la década de 1980. Hacia el sur a orillas del río Uruguay y en las Sierras Centrales de Misiones la variedad más difundida era el criollo, mientras que durante los primeros años de aquel decenio predominaba el virginia en los departamentos sureños de Oberá, Alem y San Javier. ${ }^{11}$ La metamorfosis de las lógicas empresariales determinó el pasaje hacia un modelo de exportación, con el burley como la principal variedad de cultivo. ${ }^{12}$ Como resultado de esta situación, espacialmente se observa una inserción autonomizada del sistema tabacalero con respecto al resto del frente agrario regional, donde la trayectoria socio-productiva más frecuente ha sido la de ocupante a plantador, en contraposición al recorrido tradicional de ocupante a colono sobre la base de los perennes (Dominguez, 1995). Al respecto, García sostiene:

\begin{abstract}
"La laxitud del ordenamiento territorial estatal favoreció que las tierras disponibles quedaran libres a la valorización inmobiliaria y a la competencia por su apropiación. Tal escenario propicia la disputa entre lo que, a grandes rasgos, puede caracterizarse como dos modelos productivos: por un lado, forestación a gran escala e integrada a la industria procesadora; $\mathrm{y}$, por otro, pequeña producción agrícola para el autoconsumo y el mercado. El principal cultivo de renta es el tabaco. Realizado fundamentalmente por mano de obra
\end{abstract}

\footnotetext{
Incluso, traspasó los límites nacionales y se dirigió hacia el este de Paraguay y el nordeste de Misiones, donde la expansión de la frontera agraria era comparativamente más lenta (Reboratti, 1988).

${ }^{10}$ Dominguez, Caroline (1995). Territoire, produit et conventions. La dynamique tabacote sur le front pionnier de la province argentine de Misiones. A la croisée de plusieurs mondes... Tesis Doctoral en Développement Rural, Université Toulouse Le Mirail, Toulouse.

${ }^{11} \mathrm{La}$ variedad virginia fue abandonada por diversas razones. La necesidad de capitalización que exigía su curado en estufas, gran demanda de agrotóxicos, un tamaño de explotación mayor al promedio de la zona y una cantidad de trabajo extra-predial que no se adaptaba a las características socio-económicas del área. Actualmente, este tabaco es producido en los valles salto-jujeños del Noroeste Argentino.

${ }^{12}$ Para la campaña 2006/2007, la última que se registra en la Web del Ministerio de Agricultura, un 95\% del total de tabaco acopiado en la provincia de Misiones era burley.
} 


\title{
Papeles de Trabajo $N^{\circ} 26$ - Diciembre 2013 - ISSN 1852-4508 \\ Centro de Estudios Interdisciplinarios en Etnolingüística y Antropología Socio-Cultural
}

\begin{abstract}
familiar puede posibilitar alguna oportunidad de capitalización, potencialidad que ha alentado la demanda de tierra en la frontera agrícola. Desde finales de la década de 1970, los productores familiares fueron integrándose a la dinámica del burley, aprovechando el relativo fácil asentamiento y la promoción de las compañías tabacaleras mediante la 'conquista' de los nuevos asentamientos. Este fenómeno incidió en las condiciones de reproducción de la agricultura familiar, ya que la tradicional opción por los cultivos industriales dejó de ser fundamental para la estabilización de las explotaciones en la medida que el tabaco se transformó en componente básico de su capitalización (Dominguez, 1995; Schiavoni, 2003 y Diez, 2009). Con el correr del tiempo, la sucesiva implantación de tabaco, tiende a disminuir su rendimiento y a promover la búsqueda de nuevas tierras" (2010: 237).
\end{abstract}

En este punto resulta central examinar la cuestión de la tierra. El tabaco es un cultivo de renta que permite generar ingresos rápidos año a año. A diferencia de los perennes y la reforestación que exigen, mínimamente, unos cuatro años para amortizar la inversión inicial, el burley se adapta mejor a las necesidades de reproducción del minifundio. Es por esta razón que el tabaco ha alcanzado tanto éxito en una zona con gran cantidad de pequeños productores, que casi no contratan mano de obra y donde predominan las explotaciones de menos de 25 has.

A su vez, este cultivo es altamente consumidor de espacio y rápidamente hace mermar el rendimiento de la tierra, por lo que exige de manera continua la expansión de su frontera productiva. En efecto, la ocupación de tierras fiscales y privadas es impulsada en gran medida por las propias cooperativas tabacaleras, pese a la solicitud de los permisos de ocupación por parte de algunos de estos acopiadores con el propósito de protegerse de cualquier inconveniente jurídico. Por lo general, el minifundio tabacalero en Misiones registra en promedio unas 2 ó 3 hectáreas de tabaco y el resto es destinado a la producción de subsistencia que, eventualmente, se comercializa tales como hortalizas, poroto, maíz, mandioca y algo de ganado. Ello se explica a raíz del propio proceso de subsunción ya que, una parte del ciclo anual de reproducción es complementado a partir de la producción de subsistencia en la chacra, fenómeno que vuelve aún más demandante de espacio a la pequeña producción del Alto Uruguay.

En una entrevista a uno de los agentes inmobiliarios de El Soberbio, éste afirmaba:

\begin{abstract}
"Apenas el 15\% del territorio municipal se encuentra titulado. No se sabe bien cuantos tienen permisos de ocupación y además se fue armando un mercado de compra-venta dentro de las propiedades fiscales y privadas. Entonces hay varios implicados. Los que arman sus negocios a partir de esto, el lobby tabacalero que promueve las ocupaciones para asegurar su producción y el Estado Provincial que no fiscaliza -a través del Ministerio de Ecología- porque sabe que si expulsa a esos productores es muy probable que no encuentren otro trabajo. Después, hay una idiosincrasia o una costumbre de no titular, casi todo se maneja con los famosos permisos de ocupación" (Nota de campo del 25 de Agosto de 2011).
\end{abstract}

Por su parte, el avance de la frontera del tabaco fue dejando su marca en términos de productividad. Su desplazamiento en dirección nordeste puede identificarse en el mapa 3. A medida que se extendió sobre el Alto Uruguay fue dejando suelos menos fértiles que se reconvirtieron a otras producciones, como es el caso de Colonia Aurora ${ }^{13}$, otrora muy

\footnotetext{
${ }^{13}$ Esclarecedores aportes sobre la producción tabacalera de esta zona del Alto Uruguay pueden encontrarse en Diez, Carolina (2009). Pequeños productores y agroindustria: Una etnografia en Colonia Aurora, Misiones. Tesis de Licenciatura en Antropología Social, Facultad de Humanidades y Ciencias Sociales, Universidad Nacional de Misiones, Posadas.
} 
especializada en tabaco. Actualmente, este lugar se está transformando en una cuenca láctea y cárnica a partir de la instalación de un nuevo frigorífico. El testimonio de un ex supervisor de una cooperativa tabacalera entre 1989 y 1996 permite identificar la merma de productividad en los campos del municipio de El Soberbio:

"En aquella época cada plantín de tabaco al final de la cosecha pesaba unos 140 gramos, mientras que ahora rondan entre los 80 y 100 gramos con suerte. Y le meten agroquímicos y fertilizantes a lo loco" (Nota de campo del 22 de Abril de 2009).

Al menos unos veinte productores entrevistados en la zona expresaban lo mismo con respecto a la caída del rendimiento. En el Mapa 3 se muestra la zonificación agrícola por departamento en la provincia de Misiones. En los distritos de color verde predomina la reforestación sobre la base de pino eliotti, el polígono forestal exhibe las parcelas donde se reimplantó tanto pino como eucaliptus (AMIRBY, 2008). En amarillo prevalecen los perennes, en las colonias más antiguas del sudeste y centro provincial. En turquesa los departamentos que tienen más del $20 \%$ de su territorio plantado con tabaco burley, que en Guaraní y 25 de Mayo alcanza el 50\%. Del total de la cosecha de esta variedad para la campaña 2006-2007 un 53\% se realizó en estos dos distritos.

\section{Mapa 3. Zonificación por uso agrícola predominante y expansión del tabaco entre 1980 y 2010 en la provincia de Misiones.}

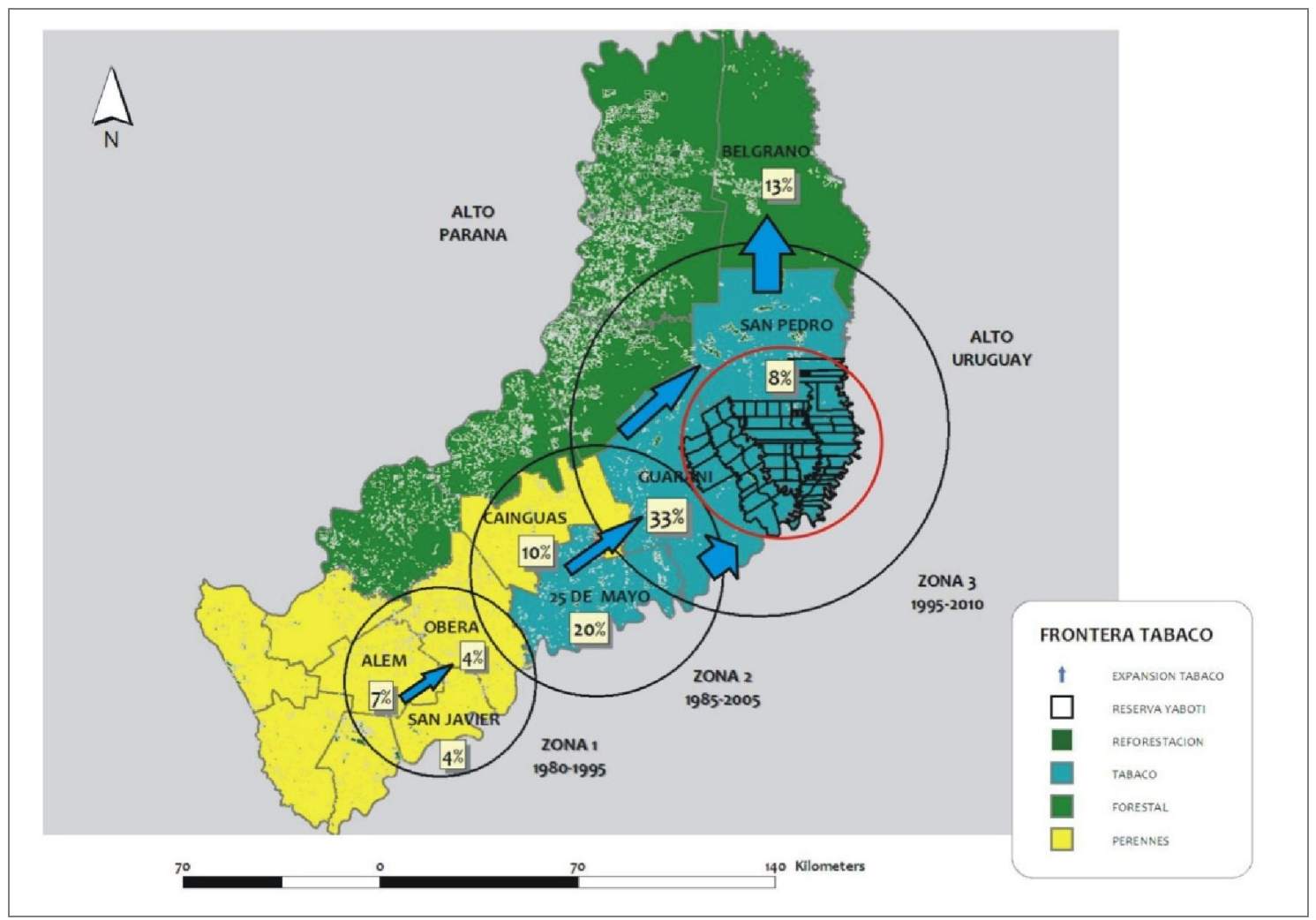

Fuente: elaboración propia en base a estadísticas del Ministerio de Agricultura (2011), Anuario Estadístico Provincial de Misiones (2008) y AMIRBY (2008)

Nota: los porcentajes refieren al aporte relativo por departamento de la cosecha de burley de la campaña 2006/2007, según datos del Ministerio de Agricultura. Vínculo Web:

http://www.minagri.gob.ar/site/agricultura/cultivos en la argentina/02=mapa produccion tabaco/02mapa $\% 20$ por $\% 20$ provincia/index.php 
Las flechas exponen la dirección de la frontera del tabaco en dirección nordeste y los tres ciclos temporales. La primera expansión entre 1980 y 1995 en la Zona 1 (Alem, Oberá y San Javier); la Zona 2 (Cainguás y 25 de Mayo) entre 1985 y 2005, área todavía tabacalera en reconversión como en el caso de Colonia Aurora y la Zona 3 (Guaraní y San Pedro) entre 1995 y 2010. Este sector agrupa al departamento con mayor producción de burley a nivel provincial (Guaraní con un $33 \%$ del total y unos 3.966 productores de los 12.719 de toda la provincia) ${ }^{14}$ y San Pedro que observa una particularidad: su crecimiento se ha visto obstruido a raíz de la constitución de la Reserva de Biósfera Yabotí, donde casi no hay explotaciones de tabaco debido a su condición de espacio en resguardo (lotes y círculo en rojo en el mapa 3). Esta corriente tabacalera ha seguido su camino hacia el norte, en el departamento Belgrano, donde predomina la reforestación de resinosos.

Cuadro 1. Parcelas rurales en los municipios del Nordeste de la Provincia de Misiones. Segmento de 1 a 25 hectáreas y aporte relativo (2009).

\begin{tabular}{|l|c|c|c|}
\hline Municipio & Total Parcelas & $\mathbf{1 - 2 5}$ has & Porcentaje \\
\hline Bernardo de Irigoyen & 662 & 489 & $73,9 \%$ \\
\hline San Pedro & 2.888 & 1.671 & $57,9 \%$ \\
\hline San Vicente & 5.143 & 3.272 & $63,6 \%$ \\
\hline El Soberbio & 3.546 & 1.942 & $54,8 \%$ \\
\hline Total & $\mathbf{1 2 . 2 3 9}$ & $\mathbf{7 . 3 7 4}$ & $\mathbf{6 0 , 3 \%}$ \\
\hline
\end{tabular}

Fuente: elaboración propia en base a la Dirección General de Catastro de Misiones (2009).

Nota: Bernardo de Irigoyen comprende la parte sur del departamento Belgrano, San Pedro es idéntico a su departamento homónimo y el departamento Guaraní agrupa a los dos últimos municipios.

Como se mencionó más arriba, la expansión del cultivo tabacalero se sustentó en la colonización relativamente reciente de tierras fiscales y privadas sobre el Nordeste Provincial. Este proceso se vio traccionado por las compañías tabacaleras que, a través de las cooperativas que se encargan del acopio, empujaron a los productores sin tierra a ocupar estas parcelas para su puesta en producción. El fenómeno de división de la tierra a través de la herencia, o bien, la búsqueda de nuevos terrenos para la reproducción doméstica, fueron conformando una estructura agraria sobre la base del minifundio orientado a la producción del burley y el autoconsumo. Mientras tanto, el latifundio fue dedicado a la explotación obrajera y, una vez talada la madera ley comercializable, fue ocupado por parte de estos mismos minifundistas productores de tabaco. Según datos de Catastro Provincial, para el año 2009 los municipios del Nordeste de Misiones observaban un $60,3 \%$ de parcelas rurales en el segmento de 1 a 25 hectáreas, siendo Bernardo de Irigoyen el de más alto aporte en este tramo $(73,9 \%)$. En el Cuadro 1 pueden verse los datos referidos.

\section{Integración vertical de la cadena y proceso de subsunción}

La integración vertical de la cadena sectorial se estructura sobre una ingeniería productiva y comercial compuesta por diferentes engranajes y escalas que es establecida, en gran parte, por los dealers multinacionales. Los verdaderos productores de tabaco, los minifundistas, abastecen

\footnotetext{
${ }^{14}$ Es de destacar que la variación interanual entre las campañas 2006 y 2007 mostró un descenso en la cantidad de productores de tabaco, de 14.785 a 12.719 unidades. Esto significó un 15\% de productores menos, de los cuales algunos se reconvirtieron y otros emigraron a los centros urbanos. De manera contraria, en los valles salto-jujeños el número de productores se elevó entre aquellos años. Por su parte, la cantidad total de productores a nivel nacional asciende a alrededor de 20.000, de los cuales un $60 \%$ se localiza en Misiones. Esto da muestra del nivel de minifundización que posee la estructura agraria del Nordeste Misionero regida a partir del cultivo del tabaco burley (Ministerio de Agricultura, 2011).
} 


\title{
Papeles de Trabajo $N^{\circ} 26$ - Diciembre 2013 - ISSN 1852-4508 \\ Centro de Estudios Interdisciplinarios en Etnolingüística y Antropología Socio-Cultural
}

a estos compradores globales a través de los acopiadores locales. A nivel nacional, la internacionalización del sector se tradujo un proceso de concentración y centralización durante los últimos tres decenios. A remolque de la mayor integración vertical, se incrementó la modalidad de agricultura bajo contrato. De este modo, los agentes internacionales que realizan el procesamiento y comercialización final fueron adquiriendo mayor control sobre el proceso de producción, mientras que los pequeños productores tabacaleros tendieron a perder su autonomía sobre el mismo. En términos generales de producción agraria nacional, Teubal sostiene: "El proceso de liberalización, apertura y desregulación, le otorgó a las grandes empresas el marco propicio para expandir su control sobre distintas áreas del sistema agroalimentario en su conjunto, obteniendo una posición dominante en lo referido al almacenaje, procesamiento, comercialización, y en la producción y provisión de semillas e insumos para la actividad agrícola" (2005: 8).

Para el caso analizado, las empresas cigarreras y especialmente los dealers multinacionales ${ }^{15}$ tienen su "brazo operativo" en las acopiadoras locales o cooperativas. En Misiones estas empresas son Tabacos Norte (integrada en tres partes iguales por Alliance One, Universal Leaf y Massalin) y la Cooperativa Tabacalera de Misiones. ${ }^{16}$ A principios de los ochenta, estas empresas encuentran en el ámbito rural misionero inmejorables condiciones de valorización, a través de la obtención de plusganancias. Como señala Domínguez (1995), esta provincia posee características agronómicas y socioeconómicas beneficiosas para la producción de tabaco. Con suelos y climas propicios, una estructura agrícola familiar flexible, buena predisposición de los productores a asimilar rápidamente las técnicas asociadas al tabaco, una organización sindical menos radicalizada que las de otras áreas productoras (Tucumán, por ejemplo), y una estructura agraria minifundista sustentada en el trabajo familiar que aseguraba una disminución del riesgo empresario por parte de los acopiadores.

Es así como comenzaron a profundizarse los procesos de subsunción indirecta de tipo real. De este modo, las empresas que manejan el acopio obtuvieron la posibilidad no sólo de determinar los precios del tabaco en bruto, sino también de supervisar todo el proceso productivo. Es de esta manera como se impusieron ciertos tiempos y cantidades de producción en el ciclo anual (determinada cantidad de tabaco que se cultiva a partir de agosto y se cosecha desde marzo) el paquete tecnológico (que incluye semillas, fertilizantes y agroquímicos) y diversas prácticas agrícolas (con un conjunto de normativas y recomendaciones a seguir). En esta utilización intensiva de los factores de producción se vio facilitada, en gran parte, gracias al papel fundamental que cumplen en campo los instructores. En una entrevista, uno de ellos señalaba:

\begin{abstract}
"Por semana hago unos 50 productores y en un mes entre 170 y 200. No doy abasto. Me fijo hasta la distancia entre los plantines, que es de $45 \mathrm{~cm}$ aproximadamente. Tampoco es que me fijo uno por uno, hay entre 15 y 18 mil plantines por hectárea. Igual ya los conozco a la mayoría desde hace tiempo, se cuál trabaja mejor o es más detallista. Generalmente no hay problemas con ningún productor" (Nota de campo del 23 de Abril de 2009).
\end{abstract}

Estos dispositivos de disciplinamiento en la esfera de la producción -como la fijación de los precios al final de la cosecha- se encuentran directamente vinculados a la subordinación económica que imponen los dealers. Estos actores multinacionales son quienes comercian el tabaco preindustrializado con las transnacionales cigarreras, ejerciendo un fuerte control sobre

\footnotetext{
${ }^{15}$ En la actualidad, son apenas dos los dealers que manejan el mercado planetario de la hoja (Alliance One y Universal), mientras que las empresas Massalin Particulares y Nobleza Piccardo son las filiales de Philip Morris y British American Tobacco, que dominan a nivel global la comercialización de cigarrillos. Generalmente, la hoja se comercializa directamente con el dealer y, eventualmente, existe algún contrato directamente con la cigarrera.

${ }^{16}$ La Cooperativa Tabacalera de Misionessurge en 1984 como respuesta de la Asociación de Plantadores de Tabaco de Misiones a los inconvenientes de comercialización que aquejaban a cerca de 500 productores locales (García y Rodríguez, 2008). Luego de un tiempo, esta cooperativa comenzó a implementar las mismas prácticas de control y disciplinamiento sobre los productores, a través de los instructores de campo, al igual que Tabacos Norte. Del mismo modo, a la hora de la negociación "cartelizan" la demanda determinando los precios de compra a los productores primarios.
} 


\title{
Papeles de Trabajo $N^{o} 26$ - Diciembre 2013 - ISSN 1852-4508 \\ Centro de Estudios Interdisciplinarios en Etnolingüística y Antropología Socio-Cultural
}

la comercialización en el mercado global y accionando en la formación de precio y la distribución del excedente. Desde mediados de los años setenta y, substancialmente, durante los años noventa, los dealers despliegan una notable influencia sobre toda la cadena sectorial en la Argentina a raíz de la orientación hacia la exportación del sector.

Fundamentalmente, existen dos formas de vinculación comercial entre los dealers y las empresas acopiadoras. La vía más usual consiste en la compra de un volumen acordado de manera previa a la cosecha, situación por la cual el dealer adelanta capital, brinda asesoramiento y predetermina la industrialización del producto al acopiador. La otra opción, menos frecuente, es convenir entre las partes una vez que el tabaco ya está acopiado. De cualquier manera, este fenómeno muestra el nivel de intervención de los dealers a lo largo de toda la cadena.

Como sostiene Gras:

\begin{abstract}
"Además de la posibilidad de acceder a la materia prima procesada sin tener que realizar grandes inversiones en activos fijos, el interés de los dealers en las cooperativas como vía de inserción en el complejo radica en el particular mecanismo de formación de precios en nuestro país" (2005: 61).
\end{abstract}

De este modo, una parte del precio de compra al productor es asumido por el Estado a través del Fondo Especial del Tabaco (FET) ${ }^{17}$, por lo que la negociación dealer-acopiador se dirime sobre el precio de acopio y no sobre el precio al productor. Inclusive, los adelantos de capital a las cooperativas se realizan en función de este precio.

En efecto, la generación de plusganancias apropiadas fundamentalmente por los dealers, y en menor medida por las acopiadoras, se sostiene en la subordinación del eslabón productivo local al sector financiero y comercializador. Además, el FET asegura el precio de venta al final del ciclo anual, produciéndose una transferencia adicional hacia dealers y cooperativas (que se sustenta en la diferencia entre el precio de acopio -que es sobre el que estos dos actores y los productores negocian- y el precio real que incluye al FET).

A partir de la década del noventa, las cooperativas tabacaleras comienzan a cumplir un papel primordial como agentes de comercialización orientada a la exportación. Son las encargadas de acopiar el burley misionero y de preindustrializarlo, antes de vendérselo a los dealers. Al mismo tiempo, los acuerdos con estos últimos permitieron el incremento de las exportaciones a la vez que las cooperativas se reorganizaron internamente y empezaron a controlar el desarrollo íntegro del proceso productivo. En la relación con el productor, se formalizaron los contratos, el adelanto de insumos y la asistencia técnica (García y Rodríguez, 2008).

Además de recibir la ayuda brindada por el FET, los dealers se convirtieron en importantes financiadores de la cosecha, por lo que, indirectamente, empezaron a cumplir el papel de acreedores, fenómeno que condicionó las acciones y decisiones de las cooperativas (Gras, 1998). El rol financiero de estos agentes trasnacionales se ha venido sustentando en el adelanto de capital con los que las cooperativas se proveen de liquidez para iniciar el ciclo productivo, aparte de la prestación de garantías a través de las cuales, las sociedades pueden acceder a créditos para tal propósito en la banca internacional.

Por su parte, los dealers tuvieron también un desempeño sustancial en la orientación tecnológica de la producción con la imposición del paquete de semillas, insumos y prácticas, lo cual elevó la calidad del producto con vistas a su exportación. De este modo, los dealers pudieron determinar las particularidades del proceso de producción de tabaco en el Alto Uruguay, además de incidir en su comercialización y financiamiento, desligándose completamente de la propiedad en la esfera productiva a través de los mencionados mecanismos de subsunción. En este sentido, las cooperativas se encargaron de activar estos dispositivos sobre la pequeña unidad doméstica

\footnotetext{
${ }^{17}$ El FET, conocido también como retorno, es un sobreprecio que paga el Estado para asegurar la viabilidad de la producción. La Ley 19.800 de 1972 establece este Fondo y reglamenta a todo el sector tabacalero. El FET es un instrumento fiscal que se financia con el aporte del fumador, a través de un impuesto compuesto de la siguiente manera: $7 \%$ del precio de venta al público; un adicional del $0,35 \%$ con destino a la obra social; y, un agregado fijo de $\$ 0,00272$ por atado de 20 unidades (García y Rodríguez, 2008).
} 


\section{Papeles de Trabajo $N^{\circ} 26$ - Diciembre 2013 - ISSN 1852-4508 \\ Centro de Estudios Interdisciplinarios en Etnolingüística y Antropología Socio-Cultural}

productora de tabaco de acuerdo a los requerimientos de los dealers. Ante este escenario, la competitividad, eficiencia y precios impuestos desde el mercado internacional -a través de los dealers- se correspondieron con el nivel de integración vertical de la cadena. En definitiva, en la actualidad la estructuración del circuito da muestra del grado de subordinación al que se someten las cooperativas $y$, en mucha mayor medida, los productores locales.

\section{Conclusiones}

El frente extractivo fue la primera forma espacial que adoptó el desarrollo regional en lo que podría denominarse como una gran formación social de fronteras durante el proceso de formación y consolidación de los estados modernos de esta zona de Sudamérica. Así, las prácticas extractivas de enclave tuvieron continuidad hasta mediados del siglo XX, con particularidades de acuerdo a los diferentes momentos de la expansión del frente agrario.

Una vez consolidada la frontera agropecuaria en el Centro-Sur Provincial, a partir de los cultivos de yerba, té y tung, y en el Alto Paraná con la producción forestal, el espacio del Nordeste sirve como "válvula de escape" para la población excedente de otras zonas de la provincia. Como se explicó más arriba, gran parte de la inmigración provenía del sur de Misiones, mientras que una porción menor lo hacía desde el Brasil. Sin embargo, las hipótesis de conflicto en torno a la frontera, de acuerdo al paradigma estatal de época, proporcionaban el marco discursivo para la promoción de la colonización tipo farmer en el Nordeste Provincial, que no logró afianzarse debido a las propias limitaciones en los planes de colonización. Por su parte, la lógica de reproducción de la frontera tabacalera configuró un novedoso tipo de trayectoria de los productores locales - de ocupante a plantador-, estableciendo notables diferencias con el recorrido más tradicional del resto de la provincia -de ocupante a colono-.

Finalmente, la consolidación del tabaco durante los noventa se desarrolla en este contexto, gracias a las ventajas agronómicas y, especialmente, a la sobreexplotación de la fuerza de trabajo local, que marca el proceso de subsunción en el área. Así, el plustrabajo apropiado por acopiadoras y dealers en la esfera de la circulación a través de la determinación de los precios de venta de la hoja en bruto favoreció la constante expansión del tabaco. Por su parte, la existencia del FET se convirtió en una fenomenal transferencia indirecta a los dealers y cooperativas, que negocian sobre el precio de acopio y no sobre el precio de producción.

En este sentido, el tipo de estructura agraria, la existencia de un cultivo de renta, el bajo nivel de organización sindical y la posibilidad de instituir una "agricultura bajo contrato" le dieron viabilidad a esta manera de producir. Asimismo, el papel de los dealers en el financiamiento de las cooperativas como el de estas mismas acopiadoras hacia los pequeños productores, estableció un esquema de adelantos de capital que incrementó la subordinación financiera a lo largo de la cadena sectorial y que contribuyó a la apropiación de los excedentes generados en la esfera productiva del minifundio.

\section{Bibliografía}

- ABÍNZANO, R. (1985): Procesos de Integración en una sociedad multiétnica. La provincia argentina de Misiones (1880-1985). Tesis de Doctorado, Universidad de Sevilla. España.

- _ (2004): “Antropología de los Procesos Transfronterizos: conocer y actuar en la región de fronteras". Cuadernos de la Frontera, Año I. Secretaría de Investigación y Postgrado, FHyCS, UNaM. Posadas.

- BARTOLOMÉ, L. (1974): "Sistemas de actividad y estrategias adaptativas en la articulación regional y nacional de colonias agrícolas étnicas: El caso Apóstoles Misiones". Departamento de Investigación Social, Facultad de Humanidades y Ciencias Sociales. Universidad Nacional de Misiones. Posadas. 

Investigación. Facultad de Humanidades y Ciencias Sociales, Universidad Nacional de Misiones. Posadas en una colonia eslava en Misiones. Editorial Universitaria Misiones, Serie CÁTEDRA. Posadas.

- BOLSI, A. (1976): “El proceso de poblamiento pionero en Misiones 1830- 1920”. Folia Histórica del Nordeste, $\mathrm{n}^{\circ}$ 2. Universidad Nacional del Nordeste. Resistencia. de Estudios Geográficos, Volumen 21, nº 80. Universidad Nacional de Cuyo. Mendoza.

- DIEZ, C. (2009): Pequeños productores y agroindustria: Una etnografía en Colonia Aurora, Misiones. Tesis de Licenciatura en Antropología Social, Facultad de Humanidades y Ciencias Sociales, Universidad Nacional de Misiones. Posadas.

- DOMINGUEZ, C. (1995): Territoire, produit et conventions. La dynamique tabacote sur le front pionnier de la province argentine de Misiones. A la croisée de plusieurs mondes... Tesis Doctoral en Développement Rural, Université Toulouse Le Mirail. Toulouse.

- $\quad$ EIDT, R. (1971): Pioneer settlement in Northeast Argentina. University of Wisconsin Press. Wisconsin.

- FOUCHER, M. (1991): Fronts et frontières. Fayard. Paris.

- FREAZA, Miguel (2000): Economía de Misiones. Aspectos y actividades relevantes. Período 1980-1999. Ministerio de Cultura y Educación, Facultad de Ciencias Económicas, Universidad Nacional de Misiones. Posadas.

- GARCIA, A. (2004): Población y territorio en Misiones. El caso de los departamentos Eldorado, Guaraní y Oberá. Tesis de Licenciatura en Geografía, Facultad de Filosofía y Letras, UBA. Buenos Aires.

- (2010): Agroindustria, agricultura familiar, políticas públicas. Contratos de producción tabacalera en Argentina y Brasil. Tesis de Doctorado en Geografía, Facultad de Filosofía y Letras, UBA. Buenos Aires.

- $\quad$ GARCIA, A. y RODRIGUEZ, E. (2008): "El Circuito del Tabaco del NOA en el contexto nacional e internacional" en Región noroeste. Competitividad, cohesión social, ambiente e inserción regional, Roccatagliata, J. (COOR). Academia Nacional de Geografía. Buenos Aires.

- GRAS, C. (1998): “Transformaciones de la agroindustria tabacalera argentina". Comercio Exterior, Volumen 48, nº 9. México (págs. 730-738).

- _ (2005): Entendiendo el ago. Trayectorias sociales y reestructuración productiva en el noroeste argentino. Editorial Biblos. Buenos Aires.

- KOSTLIN, L. (2003): Voces y Silencios en la Lucha por la Tierra en Misiones. Análisis de un caso de ocupación de tierras privadas en la provincia de Misiones. La Compañia Colonizadora Misionera, Pozo Azul, San Pedro. Tesis de Licenciatura en Antropología Social, Facultad de Humanidades y Ciencias Sociales, Universidad Nacional de Misiones. Posadas. 
- MAEDER, E. y GUTIERREZ, R: (1995): Atlas Histórico del Nordeste Argentino. Instituto de Investigaciones Geohistóricas, CONICET-FUNDANORD. Universidad Nacional del Nordeste. Resistencia.

- PALOMARES, M. (1975): Estructura Agraria de Misiones. Centro de Investigación Social (CIS), Facultad de Ciencias Sociales, UNaM. Posadas.

- RAU, Víctor (2008): "La yerba mate en Misiones (Argentina). Estructura y significados de una producción localizada". IV Congreso Internacional de la Red SIAL. Actas de Congreso. Mar del Plata.

- REBORATTI, C. (1979): "Migraciones y Frontera Agraria: Argentina y Brasil en la cuenca del Alto Paraná-Uruguay”. Desarrollo Económico, Volumen 19, n 74 . IDES. Buenos Aires.

(1981): "Causas y características del crecimiento de San Vicente". CENEP. Buenos Aires.

(1983): "Políticas públicas y redistribución de la población en una frontera agraria (Argentina)". Revista Geográfica n 97, Enero-Junio. Buenos Aires.

(1988): "Frontera interior, frontera exterior y urbanización espontánea". I Simposio Internacional de la Universidad de Varsovia sobre América Latina. Editorial Andrzej Dembicz. Varsovia.

- ROFMAN, A. (1983): Monetarismo y crisis en el Nordeste. Buenos Aires. Ediciones CEUR.

- SCHIAVONI, G. (1995a): Colonos y ocupantes. Parentesco, reciprocidad diferenciación social en la frontera agraria de Misiones. Editorial Universitaria. Posadas. (1995b): "Gestión doméstica y capitalización de pequeñas explotaciones: los productores de la frontera agraria en Misiones" en Producción doméstica y capital: estudios desde la antropología económica. Trinchero, H. (COMP). Editorial Biblos. Buenos Aires.

- _ (1999): “'Porto-Capiovara': los ocupantes agrícolas de la frontera argentino-brasileña (Misiones, Argentina)". Revista de Estudios Migratorios Latinoamericanos, año 14, n 40 (págs. 449-469).

- SCHIAVONI, PERUCCA, SCHVORER y OTERO CORREA (2006): "Desarrollo rural alternativo: las relaciones entre el estado, las ONGs y los productores de la provincia de Misiones" en Desarrollo rural. Organizaciones, instituciones y territorios MANZANAL, NEIMAN Y LATTUADA (COMPS). Ediciones CICCUS. Buenos Aires.

- TEUBAL, DOMÍNGUEZ y SABATINO (2005): “Transformaciones agrarias en la Argentina Agricultura industrial y sistema alimentario" en El campo argentino en la encrucijada. Estrategias y resistencias sociales, ecos en la ciudad, GIARRACCA y TEUBAL (COMPS). Editorial Alianza. Buenos Aires.

- TRINCHERO, H. (2000): Los dominios del demonio. Editorial EUDEBA. Buenos Aires.

- ZIMAN L. y SCHERER A. (1976): La selva vencida. Crónica del Departamento de Iguazú. Ediciones Marymar. Buenos Aires. 


\section{Fuentes estadísticas, de mapeo, planes y leyes}

- Dirección General de Catastro de Misiones (2009).

- IPEC (2008). Instituto Provincial de Estadísticas y Censos. Anuario Estadístico Provincial de Misiones del año 2008.

- Ley de Inmigración y Colonización nº 817 de 1876 ("Ley Avellaneda").

- Ley Nacional sobre venta de tierras y división de los territorios nacionales $n^{\circ} 1.265$ de 1882 .

- Ley Nacional de Promoción para el Desarrollo de las Zonas de Frontera nº 18.575 de 1970.

- Ley Nacional del Tabaco $n^{\circ} 19.800$ de 1972 (La Ley no 24.291 de 1993 restablece la vigencia de esta ley y modifica algunos artículos).

- Ley Nacional de Estímulos Fiscales para la Forestación nº 21.695 de 1977.

- Ministerio de Agricultura, Ganadería y Pesca (2011). Sistema Integrado de Información Agropecuaria. Vínculo Web: http://dev.siia.gov.ar/\#

- Provincia de Misiones (1975). Informe preliminar. Equipo técnico de la Comisión para el desarrollo e integración de las zonas y áreas de frontera. Posadas.

- (1977). Lineamientos para la formulación de un plan de desarrollo del Área de frontera Bernardo de Irigoyen. Secretaría de Planificación y Control. Posadas.

- Relevamientos del Área de Manejo Integral Reserva de Biosfera Yabotí AMIRBY- (2008). Ministerio de Ecología Recursos Naturales Renovables y Turismo, Provincia de Misiones. 